\title{
Monitoring Plasma Glucose Concentration from Interstitial Glucose Measurements for Patients at the Intensive Care Unit
}

\author{
Estefanía Aguirre-Zapata \\ Instituto Tecnológico Metropolitano Facultad de Ingenierías, \\ Grupo de Automática, Electrónica y Ciencias Computacionales. \\ Facultad de Ciencias Económicas y Administrativas, Grupo \\ de Calidad, Metrología y Producción \\ estefaniaaguirre97289@correo.itm.edu.co
}

\author{
José Fernando García-Tirado \\ Instituto Tecnológico Metropolitano \\ Facultad de Ciencias Económicas y Administrativas, Grupo \\ de Calidad, Metrología y Producción \\ josegarcia@itm.edu.co
}

(Paper type: Scientific and Technological Research. Received 09/08/2016. Probed 15/09/2016)

\begin{abstract}
The glucose homeostasis is responsible for regulating the blood glucose concentration around $100 \mathrm{mg} / \mathrm{dl}$. As soon as this mechanism is broken due to the inability of the pancreas to produce insulin, the blood glucose levels increase and patients are diagnosed with Type 1 Diabetes Mellitus (T1DM). Research has been directed towards the creation of an artificial pancreas allowing the regulation of glucose levels in blood. However, one of the main difficulties is that not all internal variables of the mathematical model can be measured directly, preventing the implementation of automatic controllers. Therefore, it is necessary to use estimation schemes to reconstruct the unknown states by using the available measurements. In the case of T1DM, the delay between the blood glucose $B_{G}$ and the interstitial glucose $I_{G}$ has a negative effect on the performance of state estimators, so the treatment of this delay is necessary either from the modeling process or by a modification of the estimation techniques. Two scenarios are discussed in this contribution. First, the $B_{G}$ is assumed to be measured from continuous glucose monitors (CGM) which introduces a measurement delay affecting the performance of the studied filter. Then, in a second scenario, the dynamic relationship between $B_{G}$ and $I_{G}$ is added to prevent the filter to deal directly with the measurement delay, then giving better results.
\end{abstract}

Keywords. EKF, state estimation, glucose homeostasis, insulin, mathematical model, T1DM.

\section{Monitoreo de la Concentración de la Glucosa Plasmática en Pacientes en Cuidados Intensivos usando Mediciones de Glucosa Intersticial}

\begin{abstract}
Resumen. La homeostasis de la glucosa es responsable de mantener la concentración de glucosa en sangre alrededor de $100 \mathrm{mg}$ / dl. Cuando este mecanismo está roto por la incapacidad del páncreas para producir insulina, los niveles de glucosa en la sangre aumentan y los pacientes son diagnosticados con Diabetes Mellitus. Por lo anterior, algunas investigaciones han apuntado hacia la creación de un páncreas artificial que permita la regulación automática de los niveles de glucosa en la sangre. Sin embargo, una de las mayores dificultades es que no todas las variables internas del modelo matemático se pueden medir directamente. Por lo anterior, es necesario el uso de esquemas de estimación para reconstruir los estados desconocidos por medio de mediciones disponibles. Sin embargo, el retardo entre $B_{G}$ e $I_{G}$ tiene un efecto negativo en el rendimiento de los estimadores de estado, por lo que el tratamiento de este retardo es necesario ya sea desde el proceso de modelado o mediante una modificación de las técnicas de estimación. De los resultados obtenidos se puede inferir que en el escenario 1 los valores estimados tienen picos que no son realistas desde el punto de vista fisiológico, esto debido al efecto negativo del retardo en la medición. De manera contraria, en el escenario 2 que incluye dinámica de la glucosa intersticial, el estimador exhibe un mejor rendimiento.
\end{abstract}

Palabras clave. DMT1, estimación de estado, FKE, homeostasis de la glucosa, insulina, modelo matemático.

\section{Introduction}

The glucose homeostasis is a natural negative feedback system responsible for blood glucose regulation. Such a regulation is performed by means of the insulin and glucagon hormones which help to lower and raise the glucose levels as needed, respectively. When glucose levels are not held at desired values, there is an indication of metabolic impairment. Diabetes Mellitus (DM) is a chronic disease appearing when such a homeostasis is broken, either due to the absence of the insulin hormone or because the body does not use the insulin hormone properly. Nowadays, although there are many variations of DM, type 1 diabetes mellitus (T1DM), type 2 diabetes mellitus (T2DM), and gestational diabetes mellitus (GDM) are the most common forms of this disease. The insulin is a hormone that facilitates the glucose uptake into the insulin sensitive tissues, so that most body cells may carry out their metabolic paths [1]. When insulin is not present in the bloodstream, most body cells are not able to catch the glucose and therefore the blood glucose concentration raises. Regarding to the epidemiological point of view, DM's projections indicate an acute raise of population through 2035 , given mainly to the western lifestyle [2].

On the other hand, according to Chase and coworkers in [3], glucose control in critically ill patients gained attention from the beginning of 2000 thanks to the work of Van der Berghe and coworkers in [4] which shown better survival rates in patients at the intensive care unit under tight glycemic control treatments. With this study, the attention of health practitioners turned on the development of better policies to monitor and control glycemic levels at the intensive care unit (ICU) even in patients without a diagnosis of diabetes.

Recent studies shown that the tighter the glucose control of the ICU patients the more dangerous becomes since hypoglycemic events are more likely to occur [5]. In this sense, although controversy is still present, it is clear that the main objective for a patient at the ICU is to maintain the glucose levels in a healthy interval provided that hypoglycemia is avoided. In [6] an interval of (140 - 
$180 \mathrm{mg} / \mathrm{dl})$ is suggested instead of $(81-108 \mathrm{mg} / \mathrm{dl})$ since the latter interval was associated to a higher mortality rate compared to the former interval.

Since the health of a critically ill patient is likely to become unstable, the continuous monitoring of the blood glucose concentration will help to avoid hyper and hypoglycemic events. Hyperglycemia is usually associated to long-term complications although in ICU patients would cause a multi systemic failure. Hypoglycemia is always way more dangerous than hyperglycemia since it would cause mortal complications since the patients are not able to react by themselves. According to the American Diabetes Association, the association upon which the Colombian health system is based on, patients at the ICU are monitored a few times a day by using conventional glucometers. Therefore, depending on the frequency of the measurements, the ability to follow the patient stability and the effects of treatments is limited. In order to offer a more continuous glucose monitoring, there exist devices implanted at the interstitial tissue able to provide glucose concentrations every five minutes on average. Such a devices are usually known as Continuous Glucose Monitors (CGM) and are nowadays being massively used to treat patients with T1DM. However, the CGM measures the glucose concentration at the interstitial tissue and not on the plasma glucose which is the variable of interest.

The development of an artificial pancreas is being a matter of interest from many years ago and a commercial device is foreseen in the near future. The artificial pancreas is an external device able to apply exact doses of insulin and glucagon using measurements of glucose concentration according to an advanced control algorithm. Although this device is mainly intended for patients with T1DM, it would also help both diabetic and non-diabetic patients at the ICU for plasma glucose control.

Model-based controllers are found to be mainly used in artificial pancreas initiatives due to its ability to deal with complex multivariate systems and the possibility of constraint handling [7]-[9]. In this sense, mathematical models are used to predict the behavior of the system of interest in order to apply the best control inputs to the real system. In the context of a biomedical device like an artificial pancreas, there exist additional engineering tasks benefited from accurate mathematical models of the glucose homeostasis like drug/treatment testing, patient monitoring, experimental design, and variables and parameter estimation, among others [10].

State estimation is a powerful tool to estimate key variables in the system dynamics by using a mathematical model and available measurements. In the context of the artificial pancreas, state estimators are needed to estimate the plasma glucose concentration, plasma insulin, interstitial insulin, among other variables, measuring solely the interstitial glucose from the CGM. Contributions about state estimation for an artificial pancreas application are found in [11],[12] and [13]. However, most of these contributions assume the measurement of the plasma glucose using the CGM which does not correspond to the human physiology since there is a considerable delay among the plasma and interstitial glucose concentration.

In this contribution, the problem of not accounting the delay between the plasma glucose and interstitial glucose is analyzed under a state estimation problem. In Section 2, the delay between plasma glucose and interstitial glucose is shown. An extended mathematical model for glucose monitoring at the ICU, taking into account the dynamics between interstitial glucose and glucose in plasma, is presented in Section 3 from previously published models. In Section 4, the design and simulation of an Extended Kalman Filter (EKF) is studied assuming first the measurement of plasma glucose and second the measurement of interstitial glucose in order to show the effect of the measurement delay over the estimation. Finally, some conclusions and future work are presented in Section 5.

\section{Problem statement}

Currently, glucose concentration monitoring in humans is made by using two types of sensors, the CGM and the glucometer, in order to control blood glucose levels by using different strategies, e.g., insulin pump, insulin injections, and oral medicines. However, it is important to understand that there is a considerable difference in the operation of both sensors. CGM is an electronic device to measure the interstitial glucose concentration (see Figure 1) every 5 minutes for 24 hours a day. A glucometer is an electronic device that allows to determine the approximate concentration of glucose in plasma by a sample taken from a finger prick, in a frequency given the recommendation by a physician or specialist.

In physiological terms, there is a time and concentration difference between interstitial glucose measurement and blood glucose measurement. In this sense, the glucose measurement obtained by the glucometer is an approximation of the real value in plasma, since the distribution of glucose toward the capillaries is not instantaneous. Similarly, when the CGM gives a measurement, it cannot be linked directly to the plasma glucose concentration without accounting for the transport and diffusion phenomena taking place between plasma and interstitial tissue.

Using the CGM as the measurement device, the problem of estimating the state can be tackled in two ways. First, it is assumed that the CGM measurements is due to a delayed version of the plasma glucose. Second, the dynamic relationship between both plasma glucose and interstitial glucose is given and therefore the interstitial glucose is assumed to be measured. The above scenarios are studied in the present paper. 
Ingenierías USBMed, Volumen 7, No. 2, Julio-Diciembre 2016

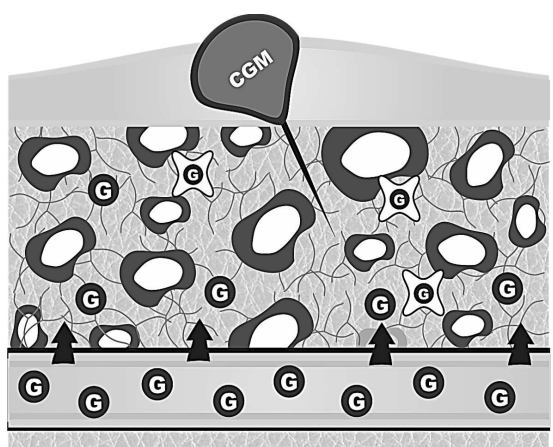

Figure 1. Diffusion of glucose since the plasma toward the interstitial fluid ((adapted from [14])

\section{Mathematical Model of Insulin-Nutrition-Glucose}

In 2010, Lin and coworkers presented a modification of the Bergman's minimal model for tight glycemic control in patients who were at the ICU [15]. A diagram showing the interaction of the different compartments and organs is shown in Figure 2. The variables used are described in the Appendix 1.

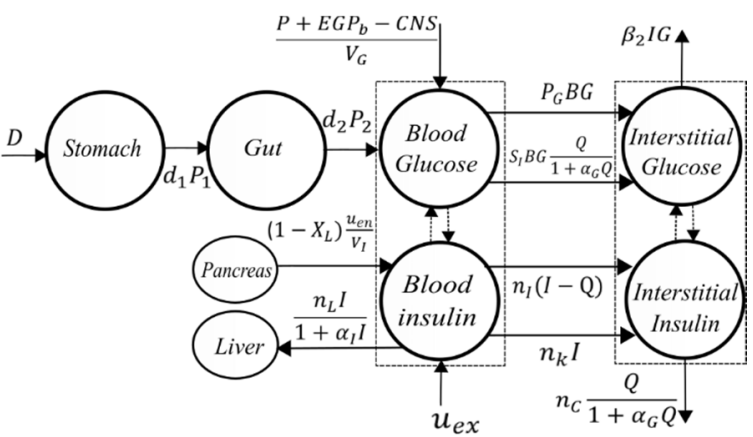

Figure 2. Model Compartments including the Interstitium.

The mathematical model under study includes five states: blood glucose $\left(B_{G}\right)$, insulin concentration in the interstice $(Q)$, insulin in plasma $(I)$, the amount of glucose in the stomach $\left(P_{1}\right)$, and the amount of glucose in the gut $\left(P_{2}\right)$. The equations of the mathematical model are summarized as follows. A description of the model variables and parameters together with its units and numerical values are presented in the Appendix 1.

$$
\begin{aligned}
& \frac{d B_{G}}{d t}=-P_{G} B_{G}-S_{I} \frac{B_{G} Q}{1+\alpha_{G} Q}+\frac{P+E G P_{b}-C N S}{V_{G}} \\
& \frac{d Q}{d t}=-n_{I}(I-Q)-n_{C} \frac{Q}{1+\alpha_{G} Q} \\
& \frac{d I}{d t}=-n_{k} I-n_{L} \frac{I}{1+\alpha_{I} I}-n_{I}(I-Q)+\frac{u_{e x}}{V_{I}} \\
& \quad+\left(1+x_{L}\right) \frac{u_{e n}}{V_{I}} \\
& \frac{d P_{1}}{d t}=-d_{1} P_{1}+D \\
& \frac{d P_{2}}{d t}=-\min \left(d_{2} P_{2}, P_{\max }\right)+d_{1} P_{1}
\end{aligned}
$$

where $P$, as it is defined in (6), corresponds to the glucose appearance into the blood stream from the enteral nutrition, $u_{e n}$ is the endogenous insulin production, and min stands for the minimum function.

$$
\begin{aligned}
& P=\min \left(d_{2} P_{2}, P_{\text {max }}\right)+P N \\
& u_{e n}=k_{1} e^{-I(t)^{\frac{k_{2}}{k_{3}}}}
\end{aligned}
$$

The model presented in (1) - (5) was proposed to control the blood glucose by infusion of exogenous glucose (in case of hypoglycemia) and insulin hormone (in case of hyperglycemia). However, although the model proposed shows a relationship existing between glucose and the hormone insulin, this model does not take into account the dynamics between interstitial glucose and glucose in plasma, what represents one of two strong assumptions. On one hand it may indicate that they are taking measurements in blood continuously (which is highly invasive for the patient and costly for the health system), or otherwise, it may mean that the interstitial glucose concentration is a real time reflection of the concentration of glucose in plasma. Therefore, a mathematical model extended by adding a differential equation allowing to establish the dynamic relationship between interstitial glucose and glucose in plasma is proposed, so that the delay can be taken into account.

The additional differential equation (8) was taken from the work of King et al [16]. This differential equation establishes a consumption and transport relationship between glucose in plasma and the glucose reaching of the interstitium of cells for to be used [16]. A change of variable $(k$ by $\beta$ ) was performed so this parameter is not confused with the gain of EKF.

$$
\frac{d I_{G}}{d t}=\beta_{1} B_{G}-\beta_{2} I_{G}
$$

where $I_{G}$ stands for interstitial glucose and $\beta_{1}$ and $\beta_{2}$ are parameters allowing to establish the relationships between the variables.

\section{State estimation}

In order to estimate the state in the glucose-insulin system, the Extended Kalman Filter (EKF) is chosen due to the ability to cope with nonlinear systems and its ease of implementation. In Figure 3, the estimation scheme used is presented. Where $D$ is the disturbance, $B_{G}$ and $I_{G}$ are the measured states according to the simulation scenario, $u_{e x}$ is the input of exogenous insulin and $x_{\text {ext }}$ is the vector of estimated state.

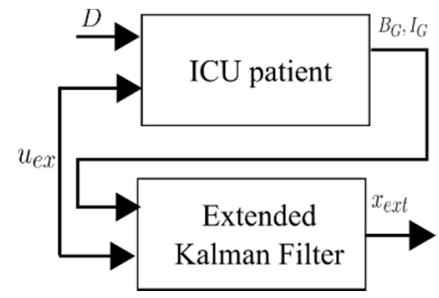

Figure 3. State estimation scheme.

The EKF is a derivation of the Kalman Filter, that is based in the linearization of the nonlinear system around a nominal trajectory state and was originally proposed by 
Stanley Schmidt in order that the KF was able to be used in nonlinear systems [17]. The EKF algorithm is summarized as follows.

\subsection{Extended Kalman Filter equations}

The EKF is composed for the equations of the nonlinear dynamic system, the initialization to the a priori estimation error covariance and priori estimated state, the linearization point to point and update equations as follows [17].

- Dynamic system equations:

$$
\begin{aligned}
& x_{k+1}=F_{k}\left(x_{k}, u_{k}, w_{k}\right) \\
& y_{k}=h_{k}\left(x_{k}, v_{k}\right) \\
& w_{k} \sim N\left(0, Q_{k}\right) \\
& v_{k} \sim N\left(0, R_{k}\right)
\end{aligned}
$$

\section{- EKF initialization:}

$x_{0}^{+}=E\left(x_{0}\right)$

$P_{0}^{+}=E\left[\left(x_{0}-\hat{x}_{0}\right)-\left(x_{0}-\hat{x}_{0}\right)^{T}\right]$

- $\quad$ for $k=1,2 \ldots n$

- Calculation of matrices of partial derivatives:

$$
\begin{aligned}
& F_{k-1}=\left.\frac{\partial f_{k-1}}{\partial x}\right|_{x_{k-1}^{+}, u_{k}} \\
& L_{k-1}=\left.\frac{\partial f_{k-1}}{\partial w}\right|_{x_{k-1}^{+}, u_{k}}
\end{aligned}
$$

- A priori state estimate and estimation error covariance:

$$
\begin{aligned}
& P_{k}^{-}=F_{k-1} P_{k-1}^{+} F_{k-1}^{T}+Q_{k-1} \\
& \hat{x}_{k}^{-}=f_{k-1}\left(\hat{x}_{k-1}^{+}, u_{k-1}\right)
\end{aligned}
$$

- Calculation of matrices of partial derivatives:

$$
\begin{aligned}
& H_{k}=\left.\frac{\partial h_{k}}{\partial x}\right|_{x_{k}^{-}, u_{k}} \\
& M_{k}=\left.\frac{\partial h_{k}}{\partial v}\right|_{\bar{x}^{-}, u_{k}}
\end{aligned}
$$

- Updating the state estimation and estimation error covariance:

$$
\begin{aligned}
K_{k} & =P_{k}^{-} H_{k}^{T}\left(H_{k} P_{k}^{-} H_{k}^{T}+R_{k}\right) \\
x_{k}^{+} & =x_{k}^{-}+K_{k}\left[y_{k}-h_{k}\left(\hat{x}_{k}^{-}\right)\right] \\
P_{k}^{+} & =\left(I-K_{k} H_{k}\right) P_{k}^{-}
\end{aligned}
$$

where $F_{k}$ is the nonlinear model, $h_{k}$ is the measurement function, $x_{k} \in \mathbb{R}^{n}$ is the system state, $u_{k} \in$ $\mathbb{R}^{m}$ is the control input, $y_{k} \in \mathbb{R}^{p}$ is the measurement vector, and $w_{k} \in \mathbb{R}^{n}$ and $v_{k} \in \mathbb{R}^{p}$ are white noises defined in (11) and (12) with $Q_{k}$ and $R_{k}$ its covariance matrices, respectively. $P_{k} \in \mathbb{R}^{n \times n}$ is the estimation error covariance matrix with $P_{0}$ its initial condition, and $K_{k}$ is the Kalman gain. Finally, $\hat{x}_{k} \in \mathbb{R}^{n}$ is the estimate of $x_{k}$. The symbols - and + on the estimates stand for the $a$ priori and the a posteriori estimates, respectively.

\section{EKF simulation.}

The simulation of the EKF was performed using Matlab $^{\circledR}$ and Simulink ${ }^{\circledR}$ release 2016 in a computer with processor intel(R) core(TM) i3-2330M of $2.20 \mathrm{GHz}$ of 64 bits.

Simulations are performed assuming a patient at the ICU using measurements from a CGM. Two scenarios are proposed. First, it is assumed the measurement of plasma glucose concentration by using the measures of CGM. Second, using (8) it is assumed the measurement of interstitial glucose. In this way, the EKF filter should estimate the state variables, i.e., plasma glucose concentration $B_{G}$, interstitial and plasma insulin $Q$ and $I$, respectively, the amount of glucose in the stomach and intestine $P_{1}$ and $P_{2}$, respectively.

\subsection{Studied scenarios}

In the following, the two studied scenarios are presented. In the first scenario, the blood glucose is assumed to be measured directly from the CGM. Although used in many reviewed contributions, this assumption has showed to be strong since the plasma glucose cannot be measured directly. Instead, the CGM gives (abdominal) interstitial glucose levels which have proven to be different from plasma levels. In a second scenario, the measurements from CGM are assumed to be taken from (abdominal) interstitial tissue. Then, the dynamic relationship between plasma glucose and interstitial glucose is added to compensate the time delay when assuming the measurement of the former.

\subsubsection{State estimation assuming the measurement of plasma glucose concentration from the} CGM.

Consider the state according to the model (1) - (7) in discrete-time after discretizing with a zero-order hold with sampling time $t_{s}=1 \mathrm{~min}$ [15]

$$
x_{k}=\left[\begin{array}{lllll}
B_{G k} & Q_{k} & I_{k} & P_{1 k} & P_{2 k}
\end{array}\right]^{T}
$$

with $x_{k}$ the discrete-time state at time $k, y_{k}=B_{G k}$, the measurement assuming plasma glucose from the CGM. The units of the state variables are $(\mathrm{mmol} / \mathrm{L}),(\mathrm{mU} /$ $L),(\mathrm{mU} / \mathrm{L}),(\mathrm{mmol})$ and $(\mathrm{mmol})$, respectively. Assume the following initial condition for the in silico patient

$$
x_{0}=\left[\begin{array}{lllll}
5 & 10.7655 & 20 & 22 & 111
\end{array}\right]^{T}
$$

The EKF was initialized as:

$$
\hat{x}_{0}=\left[\begin{array}{lllll}
5.5 & 11.2655 & 20.5 & 22.5 & 111.5
\end{array}\right]^{T}
$$

The selection of the tuning matrices for the EKF was performed by a trial-and-error procedure taking into account the root mean square error (RMSE) index. The tuning matrices $Q$ and $R$ were set as follows.

$$
Q=0.001 \cdot I_{6}
$$

Where $I_{6}$ is an identity matrix of order $6^{\text {th }}$ and 0.001 is the weight assigned heuristically.

$$
R=100
$$


Finally, the estimation error covariance $P_{k}^{+}$was initialized as an identity matrix of $6^{\text {th }}$ order as follows

$$
P_{0}^{+}=I_{6}
$$

As it was mentioned before, the plasma glucose concentration is assumed as the measured variable. However, because it is known that monitoring is being carried out by using a CGM, the diffusion mechanism from plasma to the interstitium is not accounted for. Therefore, to make the simulation realistic, a physiological delay is added as it is suggested in several studies about CGM [18]. According to a study performed by Stout and coworkers in [19], it is concluded that the time delay between the blood glucose concentration and the interstitial glucose concentration can be set in a range of $15-25 \mathrm{~min}$. For this simulation a delay $d=$ $15 \mathrm{~min}$ is considered.

In Figure 4, there is an evidence of the negative effect of the measurement delay in the performance of the EKF. In this case, the estimated variable takes about $900 \mathrm{~min}$ to start to converge to the value of the real state, which could be dangerous for decision-making in an ICU. Figure 5 shows the estimation of both the interstitial insulin and insulin in plasma. As it is seen, the estimator for the case of interstitial insulin takes approximately $700 \mathrm{~min}$ to converge the value of the real state.

In the case of the states $P_{1}$ and $P_{2}$, the measurement delay causes the same effect as in the previous states, making the estimator to take approximately $900 \mathrm{~min}$ to converge to the real state value.

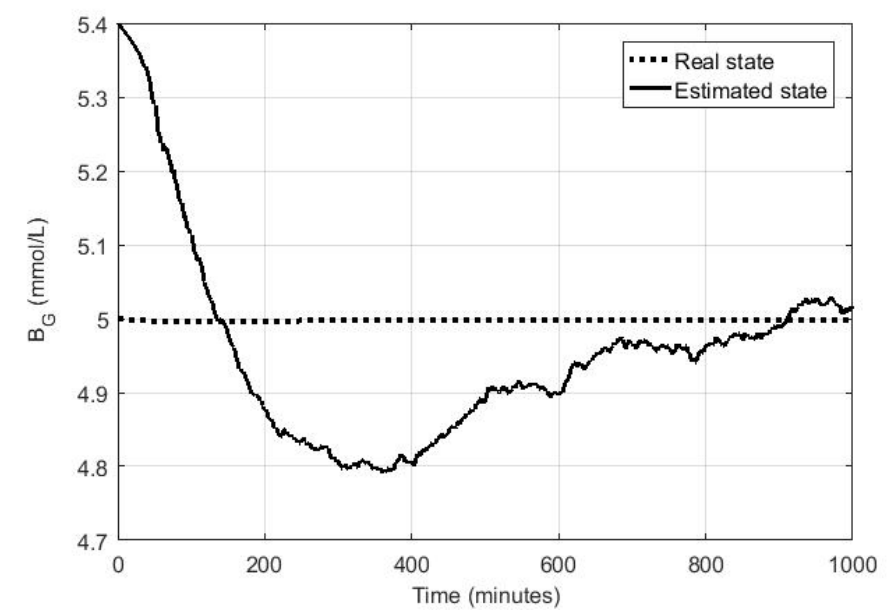

Figure 4. Blood glucose and estimated blood glucose in presence of delay in the measurement.
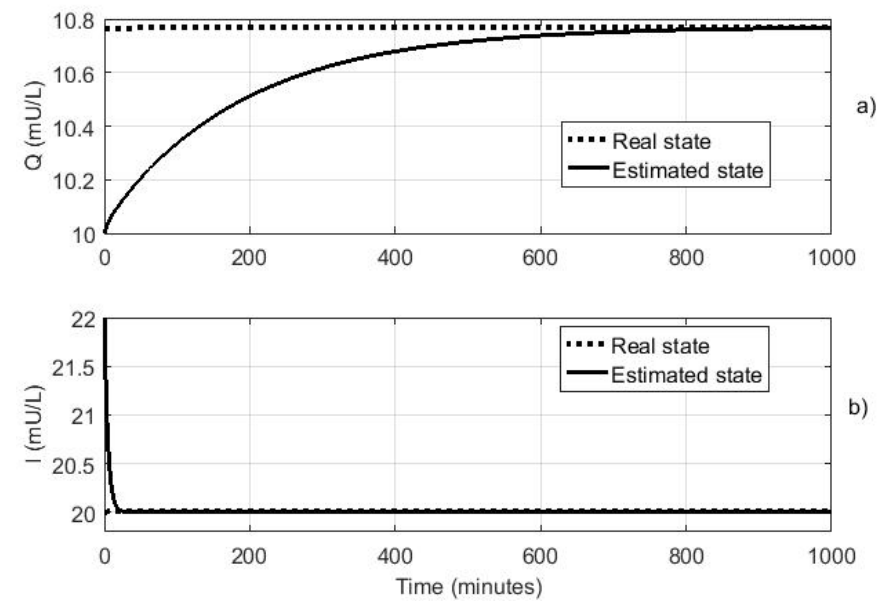

Figure 5. Interstitial insulin and plasma insulin estimated from blood glucose measurements. a) Interstitial insulin. b) Plasma insulin.
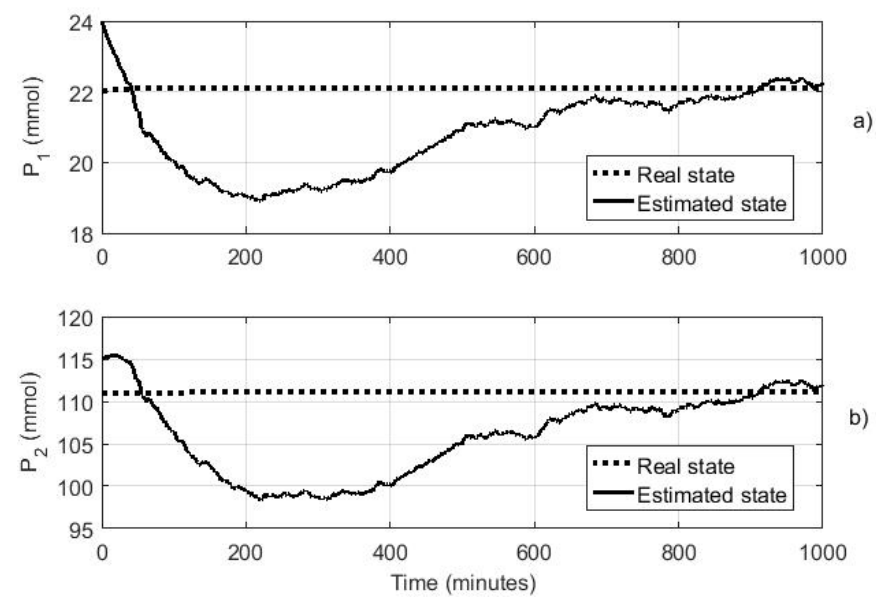

Figure 6. Glucose in the stomach and glucose in the gut estimated from blood glucose measurements. a)

Glucose in the stomach. b) Glucose in the gut.

\subsubsection{State estimation assuming the measurement of interstitial glucose concentration.}

Nowadays, there is not a way to perform direct blood glucose measurements without compromising the patient's sepsis. The only direct blood glucose measurements should be done in a clinical environment and usually take time to be analyzed in the laboratory facilities. In order to perform on-line monitoring, the CGM constitutes an interesting tool. However, it should be considered that the measurement is performed over the interstitial glucose instead of the blood glucose. In order to overcome the above issue, the dynamics from the blood glucose to the interstitial glucose is added as from (8). Then, the new state vector becomes

$$
x_{k}=\left[\begin{array}{llllll}
B_{G k} I_{G k} & Q_{k} & I_{k} & P_{1 k} & P_{2 k}
\end{array}\right]^{T}
$$

where $I_{G k}$ is the interstitial glucose at time $k$. The values of the variables are given in $(\mathrm{mmol} / \mathrm{L})$, $(\mathrm{mmol} / \mathrm{L}),(\mathrm{mU} / \mathrm{L}),(\mathrm{mU} / \mathrm{L}),(\mathrm{mmol}),(\mathrm{mmol})$, and $(\mathrm{mmol} / \mathrm{min})$, respectively. It is easy to realize that the new state vector is also locally observable around the operating point presented in (32). 
The EKF was initialized as

$$
\hat{x}_{0}=\left[\begin{array}{llllll}
5.5 & 5.5 & 11.2655 & 20.5 & 22.5 & 111.5
\end{array}\right]^{T}
$$

and the in silico patient is initialized as

$$
x_{0}=\left[\begin{array}{llllll}
5 & 5 & 10.7655 & 20 & 22 & 111
\end{array}\right]^{T}
$$

Again, the selection of the tuning matrices was performed by a trial-and-error procedure taking into account the root mean square error (RMSE). The tuning matrices $Q$ and $R$ were set as

$$
\begin{aligned}
Q & =0.001 \cdot I_{7} \\
R & =100
\end{aligned}
$$

Where $I_{7}$ is an identity matrix of $7^{\text {th }}$ order and 0.001 is the weight assigned heuristically. Finally, the estimation error covariance $P_{k}^{+}$was initialized as shown in (35).

$$
P_{0}^{+}=I_{7}
$$

To simulate the effect of the measurement noise, a Gaussian noise was assumed as follows.

$$
v_{k} \sim N(0,0.1)
$$
for.

In this work, no modeling uncertainty was accounted

In Figure 7, the concentration of blood glucose is estimated from CGM measurements. It is important to note that the estimate converges to the real value in an acceptable time because the new mathematical model included a differential equation describing the dynamics between the interstitial glucose and glucose in plasma.
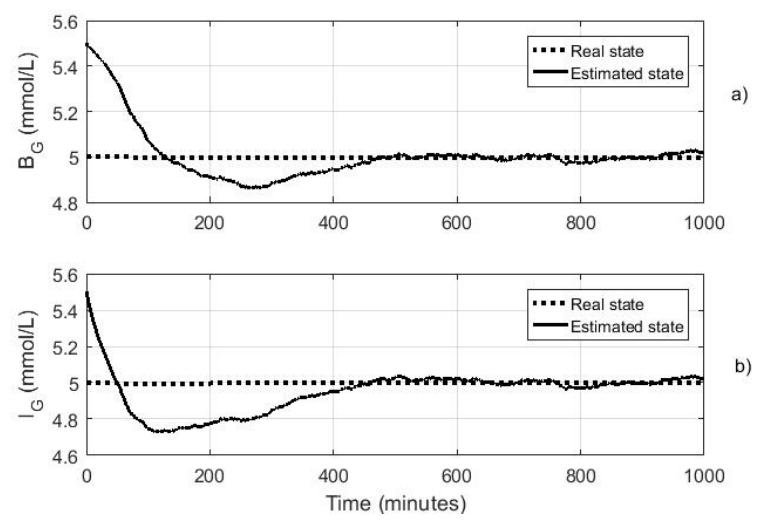

Figure 7. Blood glucose estimated from interstitial glucose measurement. a) Interstitial glucose. b) Blood glucose.

In Figure 8, it is observed that the estimated state of interstitial insulin converges in a time of approximately $650 \mathrm{~min}$ to the value of the real state. Moreover, in Figure $8 \mathrm{~b}$ it is shown that the estimated state of the plasma insulin converges in a time of about $5 \mathrm{~min}$ to the real state.

Figure 9 shows the estimation of the glucose mass in the stomach and gut. The transient behavior is considered acceptable since the evidenced overshoots are within normal operation levels. The noise is shown to be filtered also for these states.
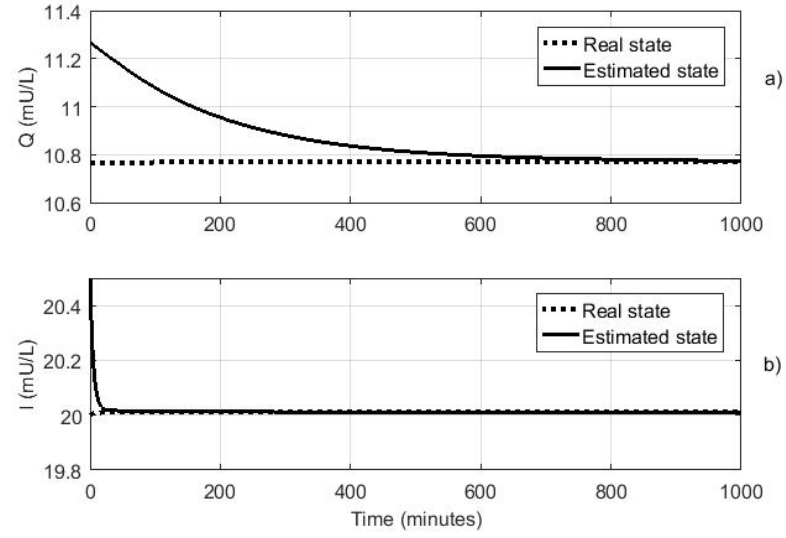

Figure 8. Interstitial insulin and insulin in plasma estimated from interstitial glucose measurement. a) Interstitial insulin estimated. b) Insulin in plasma estimated
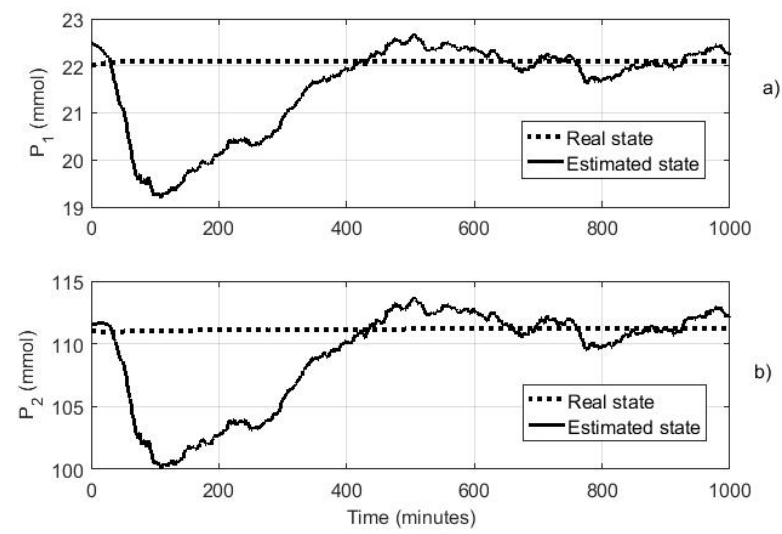

Figure 9. Glucose in the stomach and Glucose in the gut estimated from interstitial glucose measurement. a) Glucose in the stomach. b) Glucose in the gut.

\section{Conclusions}

The problem of estimating the state of the glucoseinsulin system for a patient at the ICU was studied. First, the typical assumption of measuring plasma glucose using CGM measurements is analyzed and discussed. It is shown that the problem can be tackled in two different ways. First, if CGM measurements are assumed for plasma glucose, a mechanism for accounting the delay between plasma glucose and interstitial glucose is needed. Otherwise, interstitial glucose is assumed to be measured from CGM but the dynamical relationship between plasma glucose and interstitial glucose is provided.

The results were satisfactory since it was possible to estimate the complete state of the system from a single measurement (interstitial glucose). For the states glucose in the stomach and glucose in the gut, an estimation error of $0.1 \mathrm{mmol}$ is reached.

The next step in this research is to cope with the delay measurement for estimating states by modifying or merging some of estimation techniques currently available in the literature in order to compare the results of the present contribution. Moreover, alternative nonlinear estimation strategies are to be used. 
Appendix: system parameters

\begin{tabular}{|c|c|c|c|}
\hline $\mathrm{P}$ & Value & Units & Description \\
\hline $\mathbf{B}_{\mathbf{G}}$ & State & $\mathrm{mmol} / \mathrm{L}$ & Blood glucose \\
\hline $\mathbf{I}_{\mathbf{G}}$ & State & $\mathrm{mmol} / \mathrm{L}$ & Interstitial glucose \\
\hline $\mathbf{Q}$ & State & $\mathrm{mU} / \mathrm{L}$ & Interstitial insulin \\
\hline I & State & $\mathrm{mU} / \mathrm{L}$ & Plasma insulin \\
\hline$P_{1}$ & State & mmol & Glucose in the stomach \\
\hline $\mathbf{P}_{2}$ & State & $\mathrm{mmol}$ & Glucose in the gut \\
\hline $\mathbf{P}_{\mathrm{G}}$ & 0.006 & $\min ^{-1}$ & $\begin{array}{l}\text { Patient endogenous glucose } \\
\text { removal }\end{array}$ \\
\hline $\mathbf{S}_{\mathrm{I}}$ & 0.002 & $\frac{\mathrm{L}}{\mathrm{mU}} / \mathrm{min}$ & $\begin{array}{l}\text { From former model since it is } \\
\text { identified online }\end{array}$ \\
\hline$\alpha_{\mathrm{G}}$ & 0.0154 & $\mathrm{~L} / \mathrm{mU}$ & $\begin{array}{l}\text { Saturation of insulin- } \\
\text { stimulated glucose }\end{array}$ \\
\hline $\mathbf{P}(\mathbf{t})$ & Fen & $\mathrm{mmol} / \mathrm{min}$ & External nutrition \\
\hline $\mathbf{E G}_{\mathrm{pb}}$ & 1.16 & $\mathrm{mmol} / \mathrm{min}$ & $\begin{array}{l}\text { Basal endogenous glucose } \\
\text { production }\end{array}$ \\
\hline CNS & 0.3 & $\mathrm{mmol} / \mathrm{min}$ & $\begin{array}{l}\text { Insulin independent central } \\
\text { nervous system glucose } \\
\text { uptake }\end{array}$ \\
\hline $\mathbf{V}_{\mathbf{G}}$ & 13.3 & $\mathrm{~L}$ & Glucose distribution volume \\
\hline $\mathrm{V}_{\mathrm{I}}$ & 3.15 & $\mathrm{~L}$ & Insulin distribution volume \\
\hline$\alpha_{I}$ & 0.0017 & $\mathrm{~L} / \mathrm{mU}$ & $\begin{array}{l}\text { Saturation of plasma insulin } \\
\text { disappearance }\end{array}$ \\
\hline$n_{C}$ & 0.003 & $\min ^{-1}$ & Parameter \\
\hline$n_{I}$ & 0.003 & $\min ^{-1}$ & Transcapillary difussion rate \\
\hline$n_{K}$ & 0.0542 & $\min ^{-1}$ & Kidney clearance \\
\hline$n_{L}$ & 0.1578 & $\min ^{-1}$ & $\begin{array}{lll}\begin{array}{l}\text { Patient } \\
\text { clearance }\end{array} & \text { specific liver } \\
\end{array}$ \\
\hline$u_{e x}$ & 7.5953 & $\mathrm{mU} / \mathrm{min}$ & Exogenous insulin input \\
\hline$x_{L}$ & 0.67 & [] & $\begin{array}{l}\text { First pass endogenous } \\
\text { insulin hepatic uptake }\end{array}$ \\
\hline$u_{\text {en }}$ & Fen & $\mathrm{mU} / \mathrm{min}$ & $\begin{array}{l}\text { Endogenous insulin } \\
\text { production }\end{array}$ \\
\hline$d_{1}$ & 0.0347 & $\min ^{-1}$ & Transport rate \\
\hline$d_{2}$ & 0.0069 & $\min ^{-1}$ & Transport rate \\
\hline $\mathrm{D}$ & 0.7672 & $\mathrm{mmol} / \mathrm{min}$ & $\begin{array}{l}\text { Disturbance-Amount of } \\
\text { dextrose from enteral feeding }\end{array}$ \\
\hline$P_{\max }$ & 6.11 & $\mathrm{mmol} / \mathrm{min}$ & Saturation value of $\mathbf{P}_{2}$ \\
\hline PN & 0 & $\mathrm{mmol} / \mathrm{min}$ & $\begin{array}{l}\begin{array}{l}\text { Parenteral } \\
\text { (intravenous) }\end{array} \\
\end{array}$ \\
\hline$k_{1}$ & 45.7 & $\mathrm{mU} / \mathrm{min}$ & $\begin{array}{l}\text { Base rate for endogenous } \\
\text { insulin production }\end{array}$ \\
\hline$k_{2}$ & 1.5 & [ ] & $\begin{array}{l}\text { Generic constant for } \\
\text { exponential suppression }\end{array}$ \\
\hline$k_{3}$ & 1000 & [ ] & $\begin{array}{l}\text { Generic constant for } \\
\text { exponential suppression }\end{array}$ \\
\hline$\beta_{1}$ & 0.0099 & $\min ^{-1}$ & Parameter \\
\hline$\beta_{2}$ & 0.0099 & $\min ^{-1}$ & Parameter \\
\hline
\end{tabular}

\section{References}

[1] M. Shrayyef and J. Gerich, "Principles of diabetes mellitus," in Principles of Diabetes Mellitus, P. Leonid, Ed. 2010, pp. 19-35.

[2] J. Aldworth, N. Al Bache, M. H. Hegelund, S. M. Hirst, U. Linnenkamp, D. Magliano, F. Oomatia, C. Patterson, N. Peer, A. Pritulskiy, M. M. Al Saleh, E. Shelestova, T. Tamayo, J. UsherSmith, Z. Xiuying, and Samrawit Yisahak, IDF Diabetes Atlas, 7th ed. 2015.

[3] J. Preiser, J. G. Chase, R. Hovorka, J. I. Joseph, J. S. Krinsley C. De Block, T. Desaive, L. Foubert, and P. Kalfon, "Glucose Control in the ICU : A Continuing Story," J. Diabetes Sci. Technol., vol. 10, no. 3, pp. 1-10, 2016.

[4] G. Van, M. D. Berghe, P. Wouters, F. Weekers, C. Verwaest, F. Bruyninckx, M. Schetz, D. Vlasselaers, P. Ferdinande, P. Lauwers, and others, "Intensive insulin therapy in critically ill patients," N Engl j Med, vol. 345, no. 19, 2001.

[5] P. Kalfon, B. Giraudeau, C. Ichai, A. Guerrini, N. Brechot, R Cinotti, P.-F. Dequin, B. Riu-Poulenc, P. Montravers, D. Annane, $\mathrm{H}$. Dupont, M. Sorine, and B. Riou, "Tight computerized versus conventional glucose control in the ICU: a randomized controlled trial," Intensive Care Med., vol. 40, no. 2, pp. 171-181, 2014.

[6] T. N.-S. S. Investigators, "Intensive versus Conventional Glucose Control in Critically III Patients," N. Engl. J. Med., vol. 360, no. 13, pp. 1283-1297, 2009.

[7] B. P. Kovatchev, M. Breton, C. Dalla Man, and C. Cobelli, "In Silico Preclinical Trials: A Proof of Concept in Closed-Loop Control of Type 1 Diabetes," J. Diabetes Sci. Technol., vol. 3, no. 1, pp. 4455, 2009.

[8] L. Magni, D. M. Raimondo, C. Dalla Man, G. De Nicolao, B. Kovatchev, and C. Cobelli, "Model predictive control of glucose concentration in type I diabetic patients: An in silico trial," Biomed. Signal Process. Control, vol. 4, no. 4, pp. 338-346, Oct. 2009.

[9] K. Lunze, T. Singh, M. Walter, M. D. Brendel, and S. Leonhardt, "Blood glucose control algorithms for type 1 diabetic patients: A methodological review," Biomed. Signal Process. Control, vol. 8, no. 2, pp. 107-119, Mar. 2013.

[10] J. Clain, K. Ramar, S. R. Surani, W. W. Ave, and A. Pass, "Glucose control in critical care," vol. 6, no. 9, pp. 1082-1091, 2015.

[11] C. Eberle and C. Ament, "The Unscented Kalman Filter estimates the plasma insulin from glucose measurement," BioSystems, vol. 103, no. 1, pp. 67-72, 2011.

[12] R. Gondhalekar, E. Dassau, and F. J. D. lii, "Moving-horizon-like state estimation via continuous glucose monitor feedback in MPC of an artificial pancreas for type 1 diabetes," 2014.

[13] R. Gondhalekar, E. Dassau, and F. J. Doyle, "State Estimation with Sensor Recalibrations and Asynchronous Measurements for MPC of an Artificial Pancreas to Treat T1DM," 2014.

[14] Medtronic, "Why the sensor readings are different readings GS." [Online]. Available: /www.medtronicdiabeteslatino.com. [Accessed: 29-Apr-2016].

[15] J. Lin, N. N. Razak, C. G. Pretty, A. Le, P. Docherty, J. D. Parente, G. M. Shaw, C. E. Hann, and J. G. Chase, "A physiological Intensive Control Insulin-Nutrition-Glucose ( ICING ) model validated in critically ill patients," Comput. Methods Programs Biomed, vol. 102, no. 2, pp. 192-205, 2010.

[16] C. King, S. M. Anderson, M. Breton, W. L. Clarke, and B. P. Kovatchev, "Modeling of calibration effectiveness and blood-tointerstitial glucose dynamics as potential confounders of the accuracy of continuous glucose sensors during hyperinsulinemic clamp," J. Diabetes Sci. Technol., vol. 1, no. 3, pp. 317-322, 2007.

[17] D. Simon, Optimal state estimation: Kalman, H infinity, and nonlinear approaches. John Wiley \& Sons, 2006.

[18] M. Breton and B. Kovatchev, "Analysis, Modeling, and Simulation of the Accuracy of Continuous Glucose Sensors," vol. 2, no. 5, pp. 853-862, 2008.

[19] P. J. Stout, N. Peled, B. J. Erickson, M. E. Hilgers, J. R. Racchini, and T. B. Hoegh, "Comparison of glucose levels in dermal interstitial fluid and finger capillary blood," Diabetes Technol. Ther., vol. 3, no. 1, pp. 81-90, 2001. 